\title{
STRATEGI PENGUATAN KAPASITAS KELOMPOK TANI HUTAN RAKYAT DI KABUPATEN SITUBONDO
}

\author{
(Capacity BuildingStrategy of Private Forest Group in Situbondo District) \\ Agus Supriono $^{1)}$, Cahyoadi Bowo ${ }^{1)}$, A. Syaffari Kosasih" ${ }^{2)}$, Tuti Herawati ${ }^{2)}$ \\ ${ }^{1)}$ Fakultas Pertanian Universitas Negeri Jember \\ Jl. Kalimantan No. 37 Kampus Tegal Boto, jember Jawa Timur, 68121 \\ ${ }^{2)}$ Pusat Penelitian dan Pengembangan Peningkatan Produktivitas Hutan, Bogor \\ Jl. Gunung Batu No. 5 PO Box 331 Bogor 16610 \\ Telp. 0251-8631238; Fax. 0251-7520005
}

Naskah masuk : 11 Mei 2012; Naskah diterima : 19 April 2013

\begin{abstract}
This study aims to assess capacity building strategy of private forest farmer groups in Situbondo Distric. An issue that was examined was covering internal and external factors that affecting farmer group performance. The goal was to find out effective strategies to strengthen private forest farmer groups. SWOT matrix analysis was used to find out internal, external factors, and its interaction strategy. The study identified that here wese 9 factors of internal strengths, 9 factors of internal weaknesses, 7 factors of external opportunities and 4 factors of external threats. In general, the groups are in an internal strong position and can effectively take advantage of opportunities that simultaneously minimize the negative impact of external threats. The best strategy to be chosen is expansive strategy through optimizing strengths and opportunity. Potential advantages of internal factors can be managed and to be as driving force as well as to minimize the negative impact of external threats.
\end{abstract}

Keywords: Private forest, farmer groups, swot analysis, strategy

\begin{abstract}
ABSTRAK
Penelitian ini bertujuan untuk mengkaji strategi dalam kegiatan penguatan kapasitas kelompok tani hutan rakyat di Kabupaten Situbondo yang sedang giat mengembangkan hutan di lahan milik. Permasalahan yang dikaji meliputi faktor internal dan eksternal yang mempengaruhi kinerja tani, dan strategi yang efektif dan efisien untuk menguatkan kelompok tani hutan rakyat. Pendekatan analisis yang digunakan adalah analisis matrik evaluasi faktor internal dan ekternal serta strategi interaksi SWOT. Berdasarkan hasil penelitian diketahui adanya 9 faktor kekuatan internal, 9 faktor kelemahan internal, 7 faktor peluang eksternal, serta dan 4 faktor ancaman ekternal. Secara umum kondisi kelembagaan kelompok tani berada dalam posisi kuat secara internal dan dapat efektif memanfaatkan peluang serta sekaligus meminimalkan pengaruh negatif dari ancaman eksternal yang ada. Strategi yang dipilih untuk memperkuat kelompok tani adalah strategi memanfaatkan kekutan dan peluang. Artinya bahwa potensi keunggulan yang dimiliki berupa faktor-faktor kekuatan internal yang ada dapat dikelola menjadi kekuatan pendorong guna meraih peluang-peluang serta sekaligus meminimalkan pengaruh negatif dari ancaman eksternal.
\end{abstract}

Kata kunci : Hutan rakyat, kelompok tani, analisis Swot, strategi

\section{PENDAHULUAN}

Kawasan hutan rakyat yang di Kabupaten Situbondo tersebar di beberapa kecamatan, yaitu Banyuglugur (210 Ha), Arjasa (100 Ha) dan Kendit $(98,02 \mathrm{Ha})$. Lahan di Kecamatan Kendit, khususnya di Desa Tambak Ukir yang menjadi lokasi penelitian merupakan wilayah lahan kering dengan topografi perbukitan sampai curam (Sudibyo J dan Kosasih, 2011). Hutan rakyat di Kecamatan Kendit menarik untuk dikaji, karena kebijakan pemerintah daerah yang menetapkan kecamatan ini sebagai prioritas pengembangan hutan rakyat lahan kering di Kabupaten Situbondo.

Model kebijakan pemerintah daerah kabupaten Situbondo dalam mengembangkan hutan rakyat dilakukan melalui penguatan kapasitas kelompok tani. Untuk itu perlu dilakukan kajian guna mengetahui kondisi kelompok tani secara menyeluruh. Strategi yang dirumuskan dari hasil analisis kondisi kelompok diharapkan menjadi rekomendasi dalam penguatan kapasitas kelompok. Keberdayaan dan kapasitas kelompok tani hutan rakyat yang baik akan memberikan dam- 
pak positif bagi sistem pengusahaan hutan rakyat.

Darusman dan Hardjanto (2006) menyatakan bahwa pengusahaan hutan rakyat masih merupakan jenis usaha sambilan yang dilakukan oleh keluarga petani kecil secara subsisten. Pendapatan dari hutan rakyat masih diposisikan sebagai pendapatan sampingan dan insidentil dengan kisaran tidak lebih dari $10 \%$ dari pendapatan total. Namun demikian, manfaat ekonomi hutan rakyat secara langsung dapat dirasakan nyata dan secara tidak langsung berpengaruh pada perekonomian desa. Sejalan dengan itu Zein (1998) menyatakan, setidaknya ada 2 (dua) aspek penting dalam pengusahaan hutan rakyat, yaitu sosial ekonomi dan kelestarian. Aspek sosial ekonomi mengindikasikan bahwa produk hutan rakyat merupakan andalan pemenuhan konsumsi kayu lokal dan berperan penting dalam meningkatkan kesejahteraan ekonomi masyarakat. Aspek kelestarian hutan rakyat terkait dengan fungsi hutan rakyat untuk perlindungan tata air dan pengawetan tanah.

Aspek kelestarian hutan rakyat ini ditentukan oleh cara dan aturan teknis yang dilaksanakan oleh para pengelola hutan rakyat. Aturan ini yang akan menggerakan petani hutan rakyat yang tergabung dalam kelompok untuk melaksanakan pengusahaan hutan rakyat. Untuk itu perlu kajian terhadap keragaan atau kondisi existing yang terjadi pada kelompok tani hutan rakyat.

Adapun permasalahan yang dikaji dalam penelitian ini adalah: (a) apa yang menjadi faktor internal dan eksternal kunci dalam kelompok dan (b) bagaimana rumusan strategi yang efektif dan efisien untuk penguatan kelompok secara keberlanjutan. Terkait dengan hal tersebut tujuan kajian diarahkan untuk merumuskan strategi yang efektif dan efisien. Stategi dimaksudkan untuk mengatasi berbagai kendala yang sering dihadapi oleh kelompok tani hutan rakyat.
Penelitian sejenis telah banyak dilakukan. Penelitian tentang strategi pengembangan hutan rakyat antara lain dilakukan oleh Sanudin (2009), Fauziah dan Diniyati (2011) Patabang et al. (2008), Prastwa et al. (2010). Penelitian yang mengkaji tentang kelompok tani hutan rakyat antara lain dilakukan oleh Diniyati et al. (2003), Hindra (2006), dan Diniyati (2009). Namun demikian, penelitian ini dapat mengisi kekosongan kajian ilmiah pada aspek penyusunan strategi peningkatan kepasitas kelompok tani hutan rakyat. Penelitian ini juga yang pertama dilakukan untuk aspek tersebut di Kecamatan Kendit, Kabupaten Situbondo.

\section{METODE PENELITIAN}

\section{A. Lokasi Penelitian}

Lokasi penelitian ditentukan secara sengaja di wilayah Desa Tambak Ukir-Kecamatan Kendit, Kabupaten Situbondo. Pertimbangan dalam penentuan lokasi penelitian karena desa ini merupakan lokasi prioritas penerapan kebijakan pengembangan usaha hutan milik rakyat lahan kering melalui model penguatan keberdayaan kelompok (group level).

\section{B. Pengumpulan Data}

Data yang digunakan dalam penelitian ini terdiri dari data primer dan data sekunder. Data primer dikumpulkan melalui tahap: (a) observasi kondisi fisik hutan rakyat di lokasi penelitian, (b) wawancara mendalam, (c) kelompok diskusi terarah (FGD = focus group discussio). Adapun metode yang digunakan untuk pengumpulan data sekunder melalui: (a) studi dokumentasi dan pustaka terkait, serta (b) catatan pribadi/self record.
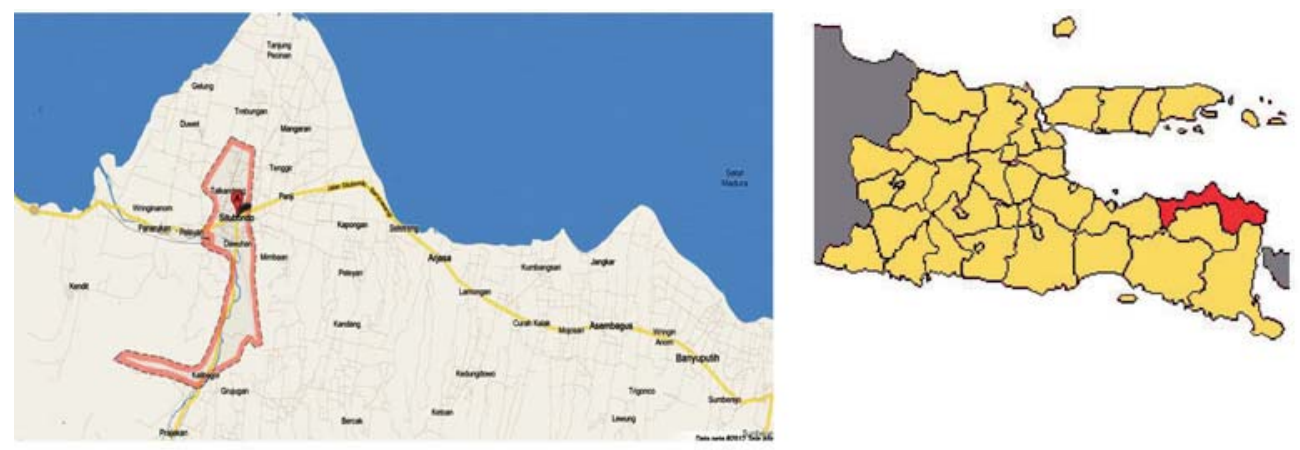

Gambar (Figure) 1. Peta Lokasi Kabupaten Situbondo (Map of Situbondo District) 
Kegiatan wawancara dilakukan terhadap informan kunci yang terdiri dari (a) pengurus kelompok tani hutan rakyat, (b) tokoh-tokoh petani hutan rakyat (c) penyuluh kehutanan, (d) penyuluh pertanian, (e) aparatur (pamong) desa Tambak Ukir, dan (f) aparatur Kecamatan Kendit.

\section{Analisis Data}

Penelitian menggunakan pendekatan deskriptif-kualitatif. Penelitian tidak berfokus pada pengujian hipotesis, akan tetapi bertujuan untuk menggambarkan realitas sosial yang kompleks dengan cara-cara mengkonstruksi realitas yang terjadi (Newman, 1997).

\section{Analisis evaluasi faktor internal dan eks- ternal}

Untuk menjawab permasalahan ke-1 yaitu mengetahui faktor-faktor internal dan eksternal kunci dalam kelompok tani hutan rakyat, dipergunakan pendekatan analisis matriks evaluasi faktor internal (matriks-EFI) dan matriks evaluasi faktor eksternal (matriks-EFE). Matriks IFE dan matriks EFE digunakan untuk menganalisis faktor-faktor internal dan eksternal serta mengklasifikasikannya menjadi kekuatan dan kelemahan, peluang dan ancaman kemudian dilakukan pembobotan. Tahap identifikasi perubah-peubah internal dan eksternal dalam matriks IFE dan EFE mengikuti teladan yang disampaikan oleh Rangkuti (2000).

\section{Grand Strategy interaksi SWOT}

Guna dapat menjawab permasalahan $k e-2$, digunakan pendekatan analisis grand strategy interaksi SWOT. Menurut Salusu (2000) dan Soesilo (2000) analisis grand strategy merupakan cara sistematis untuk mengindetifikasi strategi yang menggambarkan kecocokan paling baik diantara analisis lainnya. Analisis ini pada dasarnya merupakan interaksi dari hasil analisis evaluasi faktor internal (matriks-EFI) dan evaluasi faktor eksternal (matrik-EFE). Apabila diterapkan secara akurat, asumsi sederhana ini mempunyai dampak yang sangat besar atas rancangan suatu strategi yang berhasil. Hasil interaksi tersebut memunculkan 4 (empat) pilihan posisi strategi (positioning strategy) yaitu: (a) strategi $\mathrm{SO}$, (b) strategiWO, (c) strategi ST, dan (d) strategi WT(Tabel 1).

\section{HASIL DAN PEMBAHASAN}

\section{A. Hasil}

Identifikasi terhadap faktorfaktor kunci menunjukkan adanya 9 (sembilan) faktor kekuatan internal (strengths) dan 9 (sembilan) faktor kelemahan internal (weaknesses). Sementara itu identifikasi faktor eksternal kunci menunjukkan 7 (tujuh) faktor peluang (opportunities) dan 4 (empat) faktor ancaman (threats). Hasil perhitungan terhadap faktor internal dan eksternal lembaga kelompok tani disajikan pada Tabel 4 dan Tabel 5.

Tabel (Table) 1. Proses penentuan Grand Strategy (Grand Strategies decision process)

\begin{tabular}{|c|c|c|}
\hline 7 & Strengths (S): & Weaknesses (W): \\
\hline Opportunities $(\mathrm{O})$ : & $\begin{array}{l}\text { Nilai yang dibobot untuk strategi SO } \\
=((\text { nilai yang dibobot untuk faktor } \\
\text { kekuatan internal })+(\text { nilai yang } \\
\text { dibobot untuk faktor peluang } \\
\text { eksternal }))\end{array}$ & $\begin{array}{l}\text { Nilai yang dibobot untuk strategi WO } \\
=((\text { nilai yang dibobot untuk faktor } \\
\text { kelemahan internal })+ \text { (nilai yang } \\
\text { dibobot untuk faktor peluang } \\
\text { eksternal }))\end{array}$ \\
\hline Threats $(\mathrm{T})$ : & $\begin{array}{l}\text { Nilai yang dibobot untuk strategi ST } \\
=((\text { nilai yang dibobot untuk faktor } \\
\text { kekuatan internal })+(\text { nilai yang } \\
\text { dibobot untuk faktor ancaman } \\
\text { eksternal }))\end{array}$ & $\begin{array}{l}\text { Nilai yang dibobot untuk strategi WO } \\
=((\text { nilai yang dibobot untuk faktor } \\
\text { kelemahan internal })+(\text { nilai yang } \\
\text { dibobot untuk faktor ancaman } \\
\text { eksternal }))\end{array}$ \\
\hline
\end{tabular}

Keterangan (Remarks): Strategi terpilih adalah alternatif strategi yang memiliki nilai yang dibobot paling besar (Chosen strategy is an alternative strategy that has the greatest value weighted)

Sumber (source): Soesilo (2000) 
Tabel(Table)4. Matriks Evaluasi Faktor Internal (Matriks-EFI) (Internal Factor Evaluation matrix (Matrix EFI)

\begin{tabular}{|c|c|c|c|c|}
\hline No & $\begin{array}{c}\text { Faktor-faktor } \\
\text { internal kunci } \\
\text { (Internal factor keys) }\end{array}$ & $\begin{array}{c}\text { Bobot } \\
\text { permasalahan } \\
\text { (Problem weight) }\end{array}$ & $\begin{array}{l}\text { Urgensi } \\
\text { permasalah } \\
\text { (Problem } \\
\text { urgency) }\end{array}$ & $\begin{array}{l}\text { Nilai yang } \\
\text { dibobot } \\
\text { (the weighted } \\
\text { value) }\end{array}$ \\
\hline \multicolumn{5}{|c|}{ Kekuatan internal (Internal strengths): } \\
\hline 1 & $\begin{array}{l}\text { Dukungan fasilitas swadaya untuk kegiatan kelom- } \\
\text { pok tani. }\end{array}$ & 0,025 & 2 & 0,050 \\
\hline 2 & $\begin{array}{l}\text { Tingginya ketertarikan petani terhadap tingkat keun- } \\
\text { tungan usaha hutan rakyat. }\end{array}$ & 0,150 & 4 & 0,600 \\
\hline 3 & $\begin{array}{l}\text { Lembaga kelompok tani dapat bersinergi dengan } \\
\text { lembaga pengajian. }\end{array}$ & 0,050 & 4 & 0,200 \\
\hline 4 & Adanya dukungan pembinaan dari Dinas terkait. & 0,050 & 3 & 0,150 \\
\hline 5 & $\begin{array}{l}\text { Adanya rasa trauma akibat illegal loging di awal } \\
\text { reformasi }(1998-2000) \text { sehingga minat petani terha- } \\
\text { dap usaha hutan rakyat meningkat. }\end{array}$ & 0,025 & 3 & 0,075 \\
\hline 6 & $\begin{array}{l}\text { Cukup kuatnya ikatan kekeluargaan dan semangat } \\
\text { gotong-royong. }\end{array}$ & 0,050 & 3 & 0,150 \\
\hline 7 & $\begin{array}{l}\text { Cukup banyak pemuda tani berpengalaman organi- } \\
\text { sasi (Ansor \& NU). }\end{array}$ & 0,080 & 3 & 0,240 \\
\hline 8 & $\begin{array}{l}\text { Para petani adalah orang Madura yang memiliki se- } \\
\text { mangat suka bekerja keras, serta. }\end{array}$ & 0,030 & 3 & 0,210 \\
\hline 9 & $\begin{array}{l}\text { Sebagian besar petani memiliki lahan yang relatif } \\
\text { luas (di atas } 1 \mathrm{ha} \text { ). }\end{array}$ & 0,100 & 4 & 0,400 \\
\hline & Sub-jumlah (Sub-total) & 0,600 & & 2,075 \\
\hline \multicolumn{5}{|c|}{ Kelemahan Internal (Internal Weaknesses): } \\
\hline 1 & $\begin{array}{l}\text { Sebagian besar lahan pertanian adalah kering, ber- } \\
\text { batu, dan berlereng. }\end{array}$ & 0,080 & 2 & 0,160 \\
\hline 2 & $\begin{array}{l}\text { Akses informasi pertanian kepada petani masih relatif } \\
\text { rendah. }\end{array}$ & 0,030 & 2 & 0,060 \\
\hline 3 & $\begin{array}{l}\text { Tingkat inovasi teknologi budidaya pertanian masih } \\
\text { relatif rendah }\end{array}$ & 0,040 & 2 & 0,080 \\
\hline 4 & $\begin{array}{l}\text { Kegiatan penyuluhan tentang hutan rakyat belum } \\
\text { intensif. }\end{array}$ & 0,050 & 2 & 0,100 \\
\hline 5 & $\begin{array}{l}\text { Kegiatan pelatihan pembibitan tanaman hutan belum } \\
\text { intensif. }\end{array}$ & 0,060 & 2 & 0,120 \\
\hline 6 & $\begin{array}{l}\text { Sebagian besar petani kesulitan permodalan untuk } \\
\text { usahata hutan rakyat. }\end{array}$ & 0,050 & 1 & 0,050 \\
\hline 7 & $\begin{array}{l}\text { Tingkat pendidikan sebagian besar petani relatif } \\
\text { rendah. }\end{array}$ & 0,020 & 1 & 0,020 \\
\hline 8 & $\begin{array}{l}\text { Cukup beragamnya jenis hama yang menyerang } \\
\text { tanaman pertanian. }\end{array}$ & 0,030 & 1 & 0,030 \\
\hline 9 & $\begin{array}{l}\text { Pengetahuan petani tentang konservasi dan kesubutan } \\
\text { lahan relatif rendah. }\end{array}$ & 0,040 & 2 & 0,080 \\
\hline & Sub-jumlah (Sub-total) & 0,400 & & 0,700 \\
\hline & Jumlah-total (Total) & 1,000 & & 2,775 \\
\hline
\end{tabular}


Tabel 5. Matriks Evaluasi Faktor Eksternal (Matriks-EFE) (External Factor Evaluation matrix (Matrix EFE)

\begin{tabular}{|c|c|c|c|c|}
\hline No & $\begin{array}{c}\text { Faktor-faktor } \\
\text { internal kunci } \\
\text { (Internal factor keys) }\end{array}$ & $\begin{array}{c}\text { Bobot } \\
\text { permasalahan } \\
\text { (Problem weight) }\end{array}$ & $\begin{array}{l}\text { Urgensi } \\
\text { permasalah } \\
\text { (Problem } \\
\text { urgency) }\end{array}$ & $\begin{array}{c}\text { Nilai yang } \\
\text { dibobot } \\
\text { (the weighted } \\
\text { value) }\end{array}$ \\
\hline \multicolumn{5}{|c|}{ Peluang eksternal (External opportunities): } \\
\hline 1 & $\begin{array}{l}\text { Permintaan kayu yang tinggi di pasar domestik maupun } \\
\text { ekspor. }\end{array}$ & 0,100 & 3 & 0,300 \\
\hline 2 & $\begin{array}{l}\text { Harga kayu di tingkat petani maupun di pasar domestik } \\
\text { relatif tinggi. }\end{array}$ & 0,150 & 4 & 0,600 \\
\hline 3 & Adanya mobilisasi implementasi kebijakan GN-RHL & 0,130 & 4 & 0,520 \\
\hline 4 & $\begin{array}{l}\text { Adanya tawaran investor untuk mengusahakan hutan } \\
\text { rakyat secara kemitraan. }\end{array}$ & 0,070 & 2 & 0,140 \\
\hline 5 & $\begin{array}{l}\text { Adanya peluang usaha furniture yang memiliki pangsa } \\
\text { pasar cukup bagus. }\end{array}$ & 0,060 & 2 & 0,120 \\
\hline 6 & $\begin{array}{l}\text { Peluang berdirinya koperasi spesifik menangani per- } \\
\text { dagangan hasil hutan rakyat. }\end{array}$ & 0,040 & 1 & 0,040 \\
\hline \multirow[t]{2}{*}{7} & $\begin{array}{l}\text { Semakin kuatnya kemauan dan dukungan Pemerintah } \\
\text { Daerah maupun Pemerintah Pusat dalam pengembang- } \\
\text { an hutan rakyat. }\end{array}$ & 0,100 & 4 & 0,400 \\
\hline & Sub-jumlah (Sub-total) & 0,650 & & 2,120 \\
\hline \multicolumn{5}{|c|}{ Ancaman eksternal (External threats): } \\
\hline 1 & $\begin{array}{l}\text { Munculnya peluang praktik-pratik rente (ijon) pada } \\
\text { pemasaran hasil hutan rakyat. }\end{array}$ & 0,100 & 4 & 0,400 \\
\hline 2 & $\begin{array}{l}\text { Belum adanya upaya sertifikasi terhadap produk hutan } \\
\text { rakyat. }\end{array}$ & 0,100 & 4 & 0,400 \\
\hline 3 & $\begin{array}{l}\text { Tidak adanya kejelasan perlindungan hukum dalam } \\
\text { proses perdagangan kayu hasil hutan rakyat. }\end{array}$ & 0,090 & 4 & 0,360 \\
\hline \multirow[t]{3}{*}{4} & $\begin{array}{l}\text { Adanya praktek-praktek pungli oleh oknum lembaga } \\
\text { hukum dan keamanan dalam proses pemasaran kayu } \\
\text { hasil. }\end{array}$ & 0,060 & 3 & 0,180 \\
\hline & Sub-jumlah (Sub-total) & 0,350 & & 1,340 \\
\hline & Jumlah total (Total) & 1,000 & & 3,460 \\
\hline
\end{tabular}

\section{B. Pembahasan}

\section{Faktor internal}

Faktor-faktor kekuatan internal yang mempengaruhi kondisi kelompok tani terdiri dari: (a) dukungan fasilitas swadaya untuk kegiatan kelompok tani, (b) tingginya ketertarikan petani terhadap tingkat keuntungan usaha hutan rakyat, (c) lembaga kelompok tani dapat bersinergi dengan lembaga pengajian, (d) adanya dukungan pembinaan dari Dinas terkait, (e) adanya perasaan trauma akibat illegal loging di awal reformasi (1998-2000) sehingga minat petani terhadap usaha hutan rakyat meningkat (f) cukup kuatnya ikatan kekeluargaan dan semangat gotong-royong, (g) cukup banyak pemuda tani berpengalaman organisasi (Ansor dan NU), (h) para petani adalah orang Madura yang memiliki semangat suka bekerja keras, serta (i) sebagian besar petani memiliki lahan yang relatif luas (diatas $1 \mathrm{ha}$ ).

Adapun faktor-faktor kelemahan internal yang melingkupi kelembagaan kelompok tani hutan rakyat adalah: (a) sebagian besar lahan pertanian berupa lahan kering, berbatu, dan berlereng, (b) akses informasi pertanian masih relatif rendah, (c) tingkat inovasi teknologi budidaya pertanian masih relatif rendah, (d) kegiatan penyuluhan tentang hutan rakyat belum intensif, (e) kegiatan pelatihan pembibitan tanaman hutan belum intensif, (f) sebagian besar petani kesulitan permodalan untuk usaha hutan rakyat, (g) tingkat pendidikan sebagian besar petani relatif rendah, (h) cukup beragamnya jenis hama yang menyerang tanaman pertanian, serta (i) pengetahuan petani tentang konservasi dan kesubutan lahan relatif rendah.

Berdasarkan perhitungan total nilai yang dibobot pada matriks-IFE, dapat diketahui bahwa secara umum kondisi kelembagaan kelompok tani hutan rakyat lahan kering berada dalam posisi kuat secara internal. Hal ini diindikasikan oleh total nilai yang dibobot di dalam hasil analisis matriks-EFI yaitu lebih dari 2,50. 


\section{Faktor eksternal}

Faktor-faktor eksternal yang mempengaruhi kondisi kelompok tani terdiri dari faktor peluang dan ancaman.

Peluang yang dimiliki oleh kelompok tani hutan rakyat di Kabupaten Situbondo teridentifikasi sebanyak 7 faktor, yaitu: (a) permintaan kayu yang tinggi di pasar domestik maupun ekspor (b) harga kayu di tingkat petani maupun di pasar domestik relatif tinggi, (c) adanya mobilisasi implementasi kebijakan GN-RHL, (d) adanya tawaran investor untuk mengusahakan hutan rakyat secara kemitraan, (e) adanya peluang usaha furniture yang memiliki pangsa pasar cukup bagus, (f) peluang berdirinya koperasi spesifik menangani perdagangan hasil hutan rakyat, serta (g) semakin kuatnya kemauan dan dukungan Pemerintah Daerah maupun Pemerintah Pusat dalam pengembangan hutan rakyat.

Ancaman ekternal yang melingkupi kelembagaan kelompok tani hutan rakyat tersebut adalah: (a) munculnya peluang praktik-pratik rente (ijon) pada pemasaran hasil hutan rakyat, (b) belum adanya upaya sertifikasi terhadap produk hutan rakyat, (c) tidak adanya kejelasan perlindungan hukum dalam proses perdagangan kayu hasil hutan rakyat, serta (d) adanya praktik-praktik pungli oleh oknum lembaga hukum dan keamanan da-lam proses pemasaran kayu hasil hutan rakyat.

Berdasarkan perhitungan total nilai yang dibobot pada matriks-EFE, dapat diketahui bahwa secara umum kondisi kelembagaan kelompok tani hutan rakyat lahan kering berada dalam posisi dapat memanfaatkan peluang sekaligus meminimalkan pengaruh negatif dari ancaman eksternal. Hal ini ditunjukan oleh nilai total 3,460 atau lebih dari 2,50.

\section{Strategi penguatan kapasitas kelompok tani}

Alternatif strategi yang efektif dan efisien untuk menguatkan keberdayaan kelompok tani hutan rakyat adalah strategi SO (Strenght and Opportunity). Tabel 6 menunjukkan strategi SO dengan total nilai paling tinggi yaitu 4.195.

Tabel (Table) 6. Hasil Analisis Grand Starategy Interaksi SWOT (The Grand Strategy interaction swot analysis)

\begin{tabular}{cccc}
\hline & EFI & $\begin{array}{c}\text { Strengths }(\mathrm{S}): \\
\text { Total bobot }=2,075\end{array}$ & $\begin{array}{c}\text { Weaknesses }(\mathrm{W}): \\
\text { Total bobot }=0,700\end{array}$ \\
\hline Opportunities $(\mathrm{O}):$ & 4,195 & 2,775 \\
Total bobot $=2,120$ & 3,415 & 3,460 \\
Threats $(\mathrm{T}):$ & & \\
Total bobot $=1,340$ & &
\end{tabular}

Strategi ini menggunakan kekuatan internal untuk dimanfaatkan dalam meraih peluang eksternal atau disebut juga dengan strategi agresif. Dengan kata lain bahwa potensi keunggulan yang dimiliki, yaitu berupa faktor-faktor kekuatan internal, dapat dimanfaatkan sedemikian rupa agar dapat menjadi kekuatan pendorong (triger/move of rule).

Detail strategi SO adalah sebagai berikut:

(1) Meningkatkan minat anggota kelompok tani terhadap usaha hutan rakyat melalui pembinaan intensif, terkait: (a) tingkat keuntungan yang dapat diperoleh dari usaha hutan rakyat, (b) potensi pasar produk hutan rakyat, (c) informasi harga pasar produk hutan rakyat (secara berkala), dan (d) peluang usaha furniture (mebel).

(2) Keberadaan keunggulan bahwa: (a) sebagian besar anggota kelompok tani memiliki lahan lebih dari $1 \mathrm{Ha}$, dan (b) karakter petani hutan rakyat yang suka bekerja keras. Sebagian dari petani huran rakyat berasal dari suku Madura. Modal dasar ini dapat menjadi kekuatan dalam mempromosikan usaha hutan rakyat di wilayah penelitian agar menarik para investor luar melalui pola usaha kemitraan.

(3) Tetap memanfaatkan potensi kearifan lokal dalam rangka mengembangkan kelembagaan kelompok tani, yaitu dengan mensinergikan aktivitas kelompok tani dengan pengajian (majelis taklim).

(4) Melakukan mobilisasi sumberdaya (SDM), yaitu dengan memberikan peran yang lebih besar kepada para pemuda tani yang memiliki pengalaman berorganisasi (Pemuda Ansor dan $\mathrm{NU})$.

(5) Memanfaatkan aspek psikologis masyarakat berupa rasa trauma terhadap akibat illegal 
loging besar-besaran di awal reformasi (19982000). Kesadaran ini mendukung untuk mobilisasi implementasi kebijakan Gerakan Nasional Rehabilitasi Hutan dan Lahan (GNRHL).

(6) Memanfaatkan secara maksimal peluang-peluang yang dapat diambil dari adanya mobilisasi implementasi kebijakan GN-RHL.

(7) Memanfaatkan potensi modal sosial (social capital) berupa: (a) semangat kekeluargaan, gotong-royong, serta swadaya para petani, (b) peran para pemuda tani yang memiliki pengalaman berorganisasi (Pemuda Ansor dan NU), (c) dukungan politis Pemerintah Daerah, yaitu guna mengagas terbentuknya koperasi spesifik yang menangani perdagangan hasil hutan rakyat.

Strategi SO juga diharapkan memberikan dampak terhadap upaya mengatasi kelemahan internal dan menghindari ancaman eksternal. Keterkaitan diantara kedua aspek tersebut diuraikan sebagai berikut:

(1) strategi ke-1; dapat dipergunakan untuk mengatasi faktor kelemahan internal berupa: (a) tingkat pendidikan dan pengetahuan sebagian besar petani relatif rendah, (b) akses informasi pertanian kepada masyarakat petani masih relatif rendah, serta (c) sebagian besar lahan yang diusahakan para petani berupa lahan kering, berbatu, dan berlereng (d) kegiatan penyuluhan tentang hutan rakyat masih relatif belum intensif.

(2) strategi ke-2; dapat dipergunakan untuk mengatasi faktor kelemahan internal berupa: (a) sebagian besar petani menghadapi kesulitan permodalan (b) penguasaan teknologi budidaya masih relatif rendah.

(3) strategi ke-6; dapat dipergunakan untuk mengatasi faktor kelemahan internal berupa: (a) tingkat pendidikan dan pengetahuan sebagian besar petani relatif rendah, (b) akses informasi pertanian kepada masyarakat petani masih relatif rendah, (c) sebagian besar lahan yang diusahakan para petani berupa kering, berbatu, dan berlereng, (d) kegiatan penyuluhan tentang hutan rakyat masih relatif belum intensif, (e) kegiatan pelatihan pembibitan dan budidaya tanaman hutan relatif belum intensif, (f) penguasaan teknologi budidaya pertanian oleh para petani masih relatif rendah, dan (g) cukup banyaknya (beragamnya) jenis hama yang menyerang tanaman pertanian.
(4) strategi ke-7; dapat dipergunakan untuk menghindari faktor ancaman eksternal berupa: (a) munculnya peluang praktek-pratek rente (ijon) pada usaha hutan rakyat, (b) belum adanya sertifikasi terhadap produk hutan rakyat, (c) jaminan hukum terhadap perdagangan kayu hasil hutan rakyat masih carut-marut, dan (d) praktik-praktik pungli oleh oknum lembaga hukum dan keamanan pada perdagangan kayu hasil hutan rakyat masih relatif tinggi.

\section{KESIMPULAN}

\section{A. Kesimpulan}

1. Identifikasi faktor kunci dari kelompok tani hutan rakyat di lokasi penelitian menunjukkan adanya 9 (sembilan) faktor kekuatan internal, 9 (sembilan) faktor kelemahan internal, 7 (tujuh) faktor peluang eksternal, serta dan 4 (empat) faktor ancaman ekternal.

2. Secara umum kondisi kelompok tani hutan rakyat di lokasi penelitian berada dalam posisi kuat secara internal dan dapat efektif memanfaatkan potensi peluang serta sekaligus meminimalkan pengaruh negatif dari potensi ancaman eksternal yang ada.

3. Strategi untuk menguatkan kelompok tani hutan rakyat lahan kering di lokasi penelitian adalah strategi SO atau memanfaatkan kekuatan dan peluang yang ada. Secara teknis, strategi yang dapat dilakukan adalah : a) meningkatkan minat terhadap usaha hutan rakyat melalui pembinaan intensif; b) memanfaatkan potensi modal sosial semangat kekeluargaan, gotong-royong, serta swadaya para petani; c) meningkatkan peran para pemuda tani yang memiliki pengalaman berorganisasi (Pemuda Ansor dan NU); d) memanfaatkan dukungan Pemerintah Daerah dalam menggagas terbentuknya koperasi dan implementasi Gerakan Nasional Rehabilitasi Hutan dan Lahan .

\section{DAFTAR PUSTAKA}

Darusman, D. dan Hardjanto. 2006. Tinjauan Ekonomi Hutan Rakyat. Prosiding Seminar Hasil Penelitian Hasil Hutan. Hal 4-13. http://www. dephut.go.id/files/ ekonomi_hr.pdf. Akses tanggal 21 April 2012.

David, F.R. 1997. Manajemen Strategis: Konsep. PT. Prenhallindo. Jakarta. 
David, F. R. 2002. Manajemen Strategik. Edisi Ketujuh. Jakarta: PT Prenhallindo.

Diniyati, D. 2009. Dinamika Kelompok Tani Hutan Rakyat: Studi kasus di Desa Kertayasa, Boja dan Sukorejo. Jurnal Sosial Ekonomi. http. www. puslitsosekhut.web.id/download.php.

Diniyati, D., Suyarno, A. Badrunasar, dan T. Sutisna 2003. Kajian Sosial Ekonomi Hutan Rakyat di Desa Boja Kecamatan Majenang Kabupaten Cilacap. Prosiding Seminar Sehari. Prospek Pengembangan Hutan Rakyat di Era Otonomi Daerah. Departemen Kehutanan. Badan Penelitian dan Pengembangan Kehutanan. Loka Penelitian dan Pengembangan Hutan Monsoon Ciamis. Cilacap. Hal (74-95).

Direktorat Jenderal Rehabilitasi Lahan dan Perhutanan Sosial. 2009. Pedoman Pembangunan Areal Model Dasmikro. Jakarta: Departemen Kehutanan RI.

Fauziah, E. dan D. Diniyati. 2011. Identifikasi Faktor utama Pondok Pesantren dalam Pengembangan Hutan Rakyat. Jurnal Analisis Kebijakan Kehutanan Vol 8 No.1 April 2011. Pusat Penelitian dan Pengembangan Perubahan Iklim dan Kebijakan. Hal 77-97.

Hindra, B. 2006. Potensi dan Kelembagaan Hutan Rakyat. Prosiding Seminar Hasil Litbang Hasil Hutan 2006. Pusat Penelitian dan Pengembangan Teknologi Hasil Hutan Bogor. Hal. 1423.

Melewanto, P., Nurheni W., dan Hardjanto. 2008. Strategi Pembangunan Hutan Rakyat Pinus di Tana Toraja. Jurnal Manajemen Hutan Tropika Vol. XIV (3): Agustus 2008. Fakultas Kehutanan Institut Pertanian Bogor. Hal 97-103.

Newman, W. L. 1997. Social Research Methods; Qualitative and Qunatitative Approach. Third Edition. Boston-USA: Allyn and Bacon.
Prastawa, H, Zainal F.R., dan Hery,S. 2010. Pengembangan Hutan Pinus Masyarakat Berbasis Kemitraan Sebagai Model Pemberdayaan Masyarakat Sekitar Hutan. Jurnal Teknik Industri, Vol. 11, No. 2, Agustus 2010. Teknik Industri, Universitas Diponegoro: hal 178-183.

Rangkuti, F. 2000. Analisis SWOT: Teknik Membedah Kasus Bisnis. Reorientasi Konsep Perencanaan Strategis untuk Menghadapi Abad 21. Gramedia Pustaka Utama. Jakarta.

Republik Indonesia. 1960. Undang-Undang No. 5 Tahun 1960 tentang Pokok Agraria. Lembaran Negara RI tahun 1960 No 104. SekretariatNegara. Jakarta.

Republik Indonesia. 1999. Undang-Undang No. 41 Tahun 1999 tentang Kehutanan. Lembaran Negara RI tahun 1960 No 167. Sekretariat Negara. Jakarta

Salusu, J., 2000. Pengambilan Keputusan Strategik untuk Organisasi Publik dan Nonprofit. Cetakan Ketiga. Jakarta; PT Gramedia Widiasarana Indonesia.

Sanudin. 2009. Strategi Pengembangan Hutan Rakyat Pinus di Kabupaten Humbang Hasundutan, Sumatera Utara. Jurnal Analisis Kebijakan Kehutanan Vol. 6 No. 2, Agustus 2009 : 131 149. Pusat Litbang Sosial Ekonomi dan Kebijakan.

Soesilo, N.I. 2000. Manajemen Strategik di Sektor Publik (Pendekatan Praktis). Buku-II. Jakarta; Magister Perencanaan dan Kebijakan Publik (MPKP)-Fakultas Ekonomi-Universitas Indonesia.

Sudibyo, J. dan A.S.Kosasih. 2011. Analisa kesesuaian lahan hutan rakyat di desa Tambak Ukir, Kecamatan Kendit, Kabupaten Situbondo. Jurnal penelitian hutan tanaman Vol.8 no.2, April 2011, 125 - 133.

Zein, A.S. 1997. Aspek Pembinaan Kawasan Hutan dan Stratifikasi Hutan Rakyat. Jakarta: Rineka Jakarta. 